\title{
Increased Event-Related Potentials and Alpha-, Beta-, and Gamma-Activity Associated with Intentional Actions
}

\section{OPEN ACCESS}

Edited by:

Pierre Maurage

University of Louvain, Belgium

Reviewed by:

Michela Balconi,

Università Cattolica del Sacro Cuore,

Italy

Simon Rigoulot,

BRAMS, Canada

Nash Boutros,

Wayne State University, USA

Daniel Dumalin,

AZ Sint-Jan Brugge-Oostende AV,

Belgium

*Correspondence:

Daniela Krause

daniela.krause@med.uni-

muenchen.de

${ }^{\dagger}$ These authors have contributed equally to this work.

Specialty section:

This article was submitted to

Psychopathology,

a section of the journal

Frontiers in Psychology

Received: 24 June 2015 Accepted: 04 January 2016 Published: 22 January 2016

Citation:

Karch S, Loy F, Krause D, Schwarz S,

Kiesewetter J, Segmiller $F$,

Chrobok Al, Keeser D and Pogarell O

(2016) Increased Event-Related

Potentials and Alpha-, Betaand Gamma-Activity Associated with Intentional Actions. Front. Psychol. 7:7.

doi: 10.3389/fpsyg.2016.00007
Susanne Karch ${ }^{1 \dagger}$, Fabian Loy ${ }^{1,2+}$, Daniela Krause ${ }^{1 *}$, Sandra Schwarz ${ }^{1}$, Jan Kiesewetter ${ }^{3}$, Felix Segmiller ${ }^{1}$, Agnieszka I. Chrobok ${ }^{1}$, Daniel Keeser ${ }^{1}$ and Oliver Pogarell1

${ }^{1}$ Department of Psychiatry and Psychotherapy, Ludwig-Maximilians-University, Munich, Germany, ${ }^{2}$ Department of Child and Adolescent Psychiatry, Psychotherapy and Psychosomatic Medicine, Ludwig-Maximilians-University, Munich, Germany,

${ }^{3}$ Institute for Medical Education, Ludwig-Maximilians-University, Munich, Germany

Objective: Internally guided actions are defined as being purposeful, self-generated and offering choices between alternatives. Intentional actions are essential to reach individual goals. In previous empirical studies, internally guided actions were predominantly related to functional responses in frontal and parietal areas. The aim of the present study was to distinguish event-related potentials and oscillatory responses of intentional actions and externally guided actions. In addition, we compared neurobiological findings of the decision which action to perform with those referring to the decision whether or not to perform an action.

Methods: Twenty-eight subjects participated in adapted go/nogo paradigms, including a voluntary selection condition allowing participants to (1) freely decide whether to press the response button or (2) to decide whether they wanted to press the response button with the right index finger or the left index finger.

Results: The reaction times were increased when participants freely decided whether and how they wanted to respond compared to the go condition. Intentional processes were associated with a fronto-centrally located N2 and P3 potential. N2 and P3 amplitudes were increased during intentional actions compared to instructed responses (go). In addition, increased activity in the alpha-, beta- and gamma-frequency range was shown during voluntary behavior rather than during externally guided responses.

Conclusion: These results may indicate that an additional cognitive process is needed for intentional actions compared to instructed behavior. However, the neural responses were comparatively independent of the kind of decision that was made (1) decision which action to perform; (2) decision whether or not to perform an action).

Significance: The study demonstrates the importance of fronto-central alpha-, beta-, and gamma oscillations for voluntary behavior.

Keywords: intentional action, event-related potentials, voluntary selection, EEG, oscillatory activity 


\section{INTRODUCTION}

Executive functions can be seen as a set of cognitive abilities, e.g., planning, adaptive responses to changing environmental requirements, flexible responses, working memory, inhibition of responses, and selection between response alternatives. Executive functions refer to the many skills required to prepare for and execute complex behaviors (Ozonoff et al., 2004). Dysfunctions in the executive system impair the capability to analyze, plan, prioritize, schedule, initiate and complete an activity in a timely manner (Hosenbocus and Chahal, 2012). The psychopathology of many psychiatric diseases seems to be influenced by impairments of the executive system and are considerably associated with functional outcomes, disability and specific problem behaviors (Royall et al., 2002). Executive dysfunction has been linked to divers psychiatric conditions (Robinson et al., 2009), especially to attention deficit/hyperactivity disorder (ADHD) and to autism spectrum disorder (e.g., Happé et al., 2006; Hosenbocus and Chahal, 2012).

Fundamental aspects of executive functions are intentional actions. Intentional processes do not rely on obvious external stimuli but are self-generated, e.g., self-initiated movement and internally generated action plans. It is assumed that decisions are needed to produce intentional behaviors which are not stimulus driven (Brass and Haggard, 2008). By contrast, externally guided actions are influenced by sensory cues. Functional magnetic resonance imaging (fMRI) studies have demonstrated an association of voluntary selection processes and frontocentral areas (Turken and Swick, 1999; Ridderinkhof et al., 2004; Rushworth et al., 2007), including medial frontal areas, the supplementary motor area (SMA), the anterior cingulate cortex (ACC), and the dorsolateral prefrontal cortex (DLPFC) (Frith et al., 1991; Hyder et al., 1997; Jueptner et al., 1997; Lau et al., 2004b; Walton et al., 2004; Forstmann et al., 2006; Karch et al., 2009), the superior parietal lobule and the intraparietal sulcus (Forstmann et al., 2006; Karch et al., 2009).

Electrophysiological studies focusing on voluntary processes have demonstrated a fronto-centrally located negativity after about $200 \mathrm{~ms}$ (N2) and a positive deflection about $300 \mathrm{~ms}$ after the presentation of the task (P3; Karch et al., 2009, 2010a). In addition, the combination of electrophysiological and functional MRI results in a simultaneous EEG/fMRI study showed that the N2 amplitude was predominantly associated with BOLD responses in medial and lateral frontal brain areas, whereas functional variations of the P3 seemed to be related to both lateral frontal activities and parietal responses (Karch et al., 2009, 2010a). The function of the N2 is not yet clear: various studies focusing on executive functions demonstrated that the N2 is supposed to be a correlate of conflict detection (Van Veen and Carter, 2002), response inhibition (Falkenstein et al., 1999; Bruin et al., 2001; Bekker et al., 2004) or the detection of an endogenous mismatch process (Näätänen and Picton, 1986). The P3 seems to be associated predominantly with attention processes and the processing of information (Donchin and Coles, 1988; Kramer and Strayer, 1988; Polich and Kok, 1995), the selection between action alternatives (Gajewski et al., 2008) as well as response inhibition.
Analyses of intention-related variations in different frequency ranges are rare: one study revealed pronounced activity in high frequency ranges (>30 Hz; gamma band response) during intentional actions (Karch et al., 2012). Overall, numerous studies have demonstrated that cognitive processes, e.g., objects recognition, attention, and memory can modulate gamma band activity (Tiitinen et al., 1993; Yordanova et al., 1997; Debener et al., 2003; Herrmann and Demiralp, 2005). Increased gamma band activity can be found, for example during the concentration on auditory information as well as in subjects focusing attention on motor response preparation (Makeig, 1993; Yordanova et al., 1997) and selective attention (Tiitinen et al., 1993, 1997).

For the participation of higher association areas slower frequency ranges such as theta and alpha seem to play an important role (Klimesch, 1999; Basar et al., 2000). For example, memory processes seem to be related to alpha activity (8-12 Hz; Busch and Herrmann, 2003; Herrmann et al., 2004): responses in the alpha frequency range increase with increasing memory load (Schack and Klimesch, 2002; Busch and Herrmann, 2003). Theta activity (5-7 Hz) is also believed to be associated with hippocampal neurons and is often found during memory recall (Tesche and Karhu, 2000; Klimesch et al., 2001; Buzsaki, 2002). Altogether, the synchronous occurrence of theta/alpha/beta/gamma activity indicates the existence of distributed oscillatory systems which are interwoven with sensory and cognitive functions (Basar et al., 2000). Oscillations may act as communication networks through large populations of neurons (Basar et al., 2000).

In the current literature, decreased oscillations in cortical recordings are found in most psychiatric pathologies: a decrease of delta activity in almost all diseases, as well as frequency shifts in alpha- and the lower frequencies were recorded (Basar et al., 2015). However, there are paradoxical cases with increased oscillations, e.g., increased beta activity in patients with bipolar disorder, or an increase of gamma activity during cognitive loading in patients with schizophrenia (Basar et al., 2015). Overall, there is great evidence that gamma oscillations associated with cognitive processes are modulated in various psychiatric diseases, including ADHD (e.g.; Yordanova et al., 2001; Karch et al., 2012), schizophrenia (e.g., Leicht et al., 2010, 2015; Basar et al., 2015; Senkowski and Gallinat, 2015) as well as subjects at high risk for psychosis (Leicht et al., 2016), autism spectrum disorders (Stroganova et al., 2015), bipolar disorder (Ozerdem et al., 2010; Basar et al., 2015) and Alzheimer's disease (Basar et al., 2015). It is assumed that impairments reflect disturbed information processing and an interruption of normal neuronal synchronization, e.g., caused by a dysfunctional GABA/glutamate system. It has been suggested that these processes contribute to impairments in the integration of cognitive and affective information (Ozerdem et al., 2010). Brass and Haggard (2008) proposed a model in order to distinguish different aspects of intentional action: the decision about which action to execute (what component), the decision about when to execute an action (when component), and the decision about whether to execute an action or not (whether component; Brass and Haggard, 2008). The what component can be addressed when participants can choose between various response alternatives (Botvinick et al., 
2001; Nachev et al., 2007). The rostral cingulate zone and the pre-SMA seem to be especially related to the what component (Lau et al., 2004b; Walton et al., 2004; Krieghoff et al., 2009). The when component is related to the time-point of decision (Cunnington et al., 2003; Lau et al., 2004a). The superior medial frontal gyrus probably could be more clearly activated in the timing component (when; Krieghoff et al., 2009). In daily life subjects often have to decide on their own whether they should act or not. However, the whether component has hardly been investigated so far; a specific region in the fronto-median cortex might be related to these processes (Brass and Haggard, 2007).

The aim of the present study was to examine electrophysiological responses associated with intentional actions. Especially the influence of different aspects of voluntary actions (1) the decision about which action to execute (what component) (2) the decision to act or not (whether component) on electrophysiological responses will be addressed. We hypothesized that voluntary selection processes are related to enhanced N2 and P3 amplitudes in fronto-central brain areas (e.g., Näätänen and Picton, 1986; Gajewski et al., 2008). In addition, alpha-, beta, and gamma-band activity is supposed to be increased in frontal areas during intentional actions compared to externally guided responses.

\section{MATERIALS AND METHODS}

\section{Subjects}

Twenty-eight healthy male subjects without any neurologic or psychiatric diagnosis (rated by a standardized questionnaire) participated in the EEG experiment. We included only males because several former studies demonstrated a gender effect for electrophysiological responses (Deldin et al., 1994). Several questionnaires were used to determine their actual mental state, e.g., the Beck Depression Inventory (BDI; Beck and Steer, 1987). One participant was excluded from any further analysis because the BDI score was higher than cut-off (cut-off >14). Hence, 27 participants (aged between 20 and 34 years; mean age: $24.0 \pm 2.71$ years; mean BDI score: $2.70 \pm 2.49$ ) were included in the EEG analysis. Participants were recruited from an academic environment (education: mean: $16.4 \pm 1.79$ years; verbal intelligence: mean: $118.4 \pm 8.55)$. The executive abilities of participants were not examined before the participation in the study.

The sample was randomly divided into two sub-samples; these groups were instructed to carry out two different versions of the same task (see paradigm; paradigm $+/-$ and paradigm $\mathrm{R} / \mathrm{L}$ ). The two groups did not differ regarding age (paradigm $+/-$ : number of participants: 14 ; mean age: $24.8 \pm 3.31$; paradigm R/L: number of participants: 13 ; mean age: $23.2 \pm 1.64 ; p=0.139$ ), education (paradigm $+/-$ : mean: $16.6 \pm 1.96$ years; paradigm $\mathrm{R} / \mathrm{L}$ : mean: $16.3 \pm 1.64$ years; $p=0.631$ ) and verbal intelligence (paradigm +/-: mean: $117.5 \pm 9.21$; paradigm $\mathrm{R} / \mathrm{L}$ : mean: $119.3 \pm 8.1$; $p=0.593)$.

The study was approved by the local ethics committee of the Ludwig-Maximilians-University Munich. The investigation was carried out in accordance with the Declaration of Helsinki.
Written informed consent was obtained from each participant after procedures had been fully explained. Each subject was paid $€ 20$ for participation in the study.

\section{Procedure, Paradigm, and Analysis of Behavioral Data}

All subjects performed an adapted go/nogo task where auditory stimuli consisted of sinusoidal tones (duration: $50 \mathrm{~ms}$, pressure level: $100 \mathrm{~dB}$ ) of three differential pitches, delivered binaurally via headphones. Tones were presented pairwise at intervals of $1000 \mathrm{~ms}$. The interval between trials lasted $2000 \mathrm{~ms}$. The go condition comprised the combination of a middle frequency tone $(1000 \mathrm{~Hz}$; cue stimulus) followed by a high frequency tone $(1300 \mathrm{~Hz})$. Subjects were instructed to press a response button with their right index finger and respond as quick as possible after the stimuli were presented, while minimizing any errors. In the nogo task the tone with the middle frequency (cue stimulus) was followed by a low frequency tone $(800 \mathrm{~Hz})$. During this condition, the prepared behavioral response was to be inhibited. In the voluntary selection condition, the cue stimulus was followed by the tone with an identical frequency $(1000 \mathrm{~Hz}$; selection; information about the paradigm see also Karch et al., 2009, 2012). Instructions regarding the voluntary selection condition differed between the two versions of the paradigm: in the first version, participants were instructed to freely decide whether to press the response button (selection + ) or not (selection-) during the voluntary selection task (paradigm $+/-$ ). Participants were asked to decide separately in each trial of the voluntary selection condition whether they wanted to respond or not. Subjects were told that the ratio selection+/selection- should be approximately equally often. In addition, subjects were asked not to count how often they pressed the button and not to alternate between button press and not press. In paradigm $R / L$, two response buttons were provided. Subjects were instructed to decide whether they wanted to press a response button with the left (selection_L) or the right (selection_R) index finger. Participants were instructed to press the response button with the right and left index finger more or less equally often without counting the responses (see Figure 1).

In addition, both paradigms included a passive listening task which served as control condition. During the control condition, the tone with the low-frequency was presented first, indicating that no behavioral response was necessary regardless of which tone was presented next (control condition: 800-1000 Hz). All conditions were presented in pseudo-randomized order. The go condition was presented 160 times, the other conditions were presented 80 times, with an interstimulus interval of 3 s. Prior to the EEG session, all subjects received a practice block in order to ensure that the instructions had been fully understood (see also Karch et al., 2009, 2012).

Auditory stimuli were generated using the Presentation software package (version 14.2) and conducted via a set of headphones placed over the subjects' ears. Participants kept their right index finger mounted on the button of the response box. During paradigm $\mathrm{R} / \mathrm{L}$, subjects were also instructed to keep their left index finger on the second response button. 


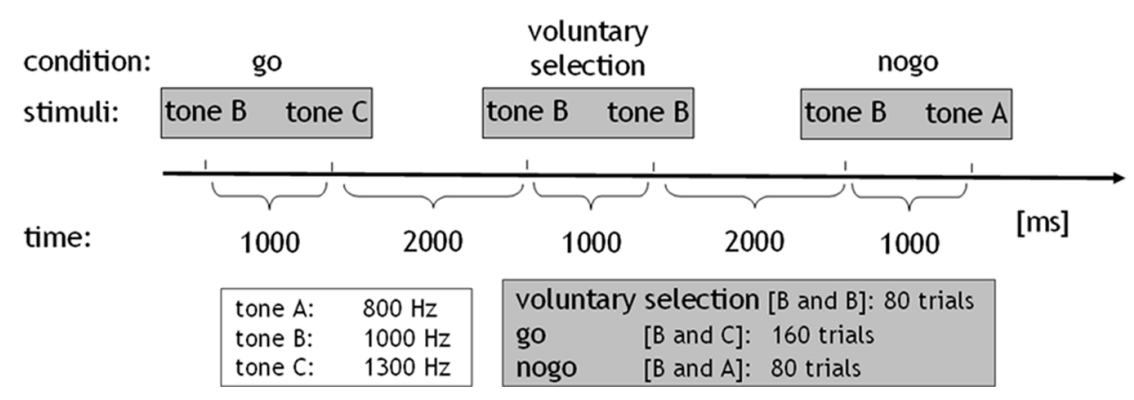

FIGURE 1 | Paradigm: sinusoidal tones of three differential pitches were presented (duration: $\mathbf{5 0}$ ms, pressure level: $\mathbf{1 0 0} \mathbf{~ d B ) . ~ T h e ~ t o n e s ~ w e r e ~ p r e s e n t e d ~}$ in pairs at intervals of $1000 \mathrm{~ms}$. The interval between trials lasted $2000 \mathrm{~ms}$. The go condition comprised the combination of the middle-frequency tone (tone b: $1000 \mathrm{~Hz}$; cue stimulus) followed by the high-frequency tone (tone c: $1300 \mathrm{~Hz}$ ). In the nogo task, the cue stimulus was followed by a low-frequency tone (tone a: $800 \mathrm{~Hz}$ ). In the voluntary selection condition, the cue stimulus was followed by the tone with a same frequency. The go condition was presented 160 times, nogo, and voluntary selection were presented 80 times.

\section{Behavioral Data}

Reaction times, errors of omission (during go task) and errors of commission (during nogo condition and passive listening task) were recorded with the Presentation software. Any response delayed by more than $1500 \mathrm{~ms}$ after the stimulus was counted as error during the go condition. During the voluntary selection condition of paradigm $+/-$, behavioral responses during the interval 0-1500 ms after stimulus presentation were counted as selection+; trials without behavioral response within the first $1500 \mathrm{~ms}$ after stimulus presentation were counted as selection-. In paradigm $\mathrm{R} / \mathrm{L}$, responses with the right and the left index finger were recorded during the voluntary selection task. The mean reaction times were calculated separately for go and voluntary selection. Behavioral data (response times; error rates) were compared between conditions with ANOVA (within subject factors of paradigm $+/-$ : go; selection + ; within subject factors of paradigm R/L: selection; $g o$ ). In addition, $t$-tests were calculated in order to examine differences regarding reaction time, percentage of correct responses and the error rate between paradigm $+/-$ and paradigm $\mathrm{R} / \mathrm{L}$.

\section{EEG Acquisition and Data Analysis}

The EEG was recorded with 32 electrodes (Neuroscan Synamps) using an electrode cap; $\mathrm{Cz}$ served as reference. Electrodes were positioned according to the International 10/20 system including the following electrodes: $\mathrm{Fz}, \mathrm{Cz}, \mathrm{Pz}, \mathrm{Fp} 1, \mathrm{Fp} 2, \mathrm{~F} 3, \mathrm{~F} 4, \mathrm{~F} 7$, F8, C3, C4, Cp5, Cp6, P3, P4, P9, P10, T5, T6, T3, T4, O1, O2, A1, A2, EOG, T1, T2, Fc5, Fc6, Fc1, Fc2. Data were collected with a sampling rate of $1000 \mathrm{~Hz}$ and without any filter during acquisition. Impedances were maintained below $5 \mathrm{k} \Omega$. Participants were asked to stay calm and keep their eyes closed during the task. Recording took place in a sound-attenuated and electrically shielded room.

Pre-processing and data analyses were done with the Vision Analyzer Software (Brain Products, Munich). A common average reference was used. EEG data were filtered with a $1 \mathrm{~Hz}$ highpass filter (slope $24 \mathrm{~dB} / \mathrm{oct}$ ), a $100 \mathrm{~Hz}$ low-pass filter (slope $24 \mathrm{~dB} /$ oct); a notch filter was not used. Eye-blinks were detected automatically and corrected using the correction of Graton
\& Coles using Fp2 as reference. EEG data were segmented into $2000 \mathrm{~ms}$ epochs time-locked to the onset of the second stimulus of each pair of tones, separately for each different condition (voluntary selection, go, nogo). The sampling epoch commenced $1000 \mathrm{~ms}$ before the presentation of the second tone that indicated which task was to be performed. An amplitude criterion $( \pm 70 \mu \mathrm{V})$ was used for artifact rejection involving $F z$, $C z$, and $P z$. Baseline correction was done using the $200 \mathrm{~ms}$ interval before the second stimulus of each pair of tones. ERP wave-shapes were averaged separately for go, nogo, voluntary selection condition. Trials with incorrect responses were rejected prior to averaging. All wave-shapes included at least 30 averages.

In the paradigm $+/-94.2 \%$ of go trials $(M=150.7$ trials), $94.8 \%$ of the nogo trials $(M=75.8)$ and $96.6 \%$ of the voluntary condition ( $M=77.3$ trials) were included on average for the analyses. Concerning the R/L paradigm $94.9 \%$ of go trials ( $M=151.8$ trials), $96.9 \%$ of the nogo trials ( $M=77.5$ trials) and $91.8 \%$ of the voluntary condition ( $M=73.4$ trials) were included on average for the analyses.

\section{Statistics}

SPSS 18.0 program was used for statistical analysis. The significance level was $0.05, p$-values between 0.05 and 0.1 were marked as a trend.

\section{Event-Related Potentials}

ERPs (N2 and P3) were examined at fronto-centro-parietal electrodes ( $\mathrm{Fz}, \mathrm{Cz}, \mathrm{Pz})$. The $\mathrm{N} 2$ was defined as the largest relative minimum of the ERP in the search window of 160-230 ms. The P3 was defined as the largest relative maximum of the ERP 230-550 ms after the presentation of the respective task. ANOVAs were run on the maximum ERP-amplitude in each search window (N2, P3) with two within subject factors task (voluntary selection, nogo, go) and electrode position $(\mathrm{Fz}, \mathrm{Cz}, \mathrm{Pz})$. Because ANOVAs are not robust to violations of sphericity we checked for each within subject factor whether Mauchly's test was significant. If so, the Greenhouse-Geisser corrected values for any effects involving this factor were reported. Post hoc $t$ tests were used in case of significant within subjects factors in order to analyze which task conditions and electrodes differed 
significantly from each other. Based on $3 \times 3$ task conditions, nine different tests were performed. The results of the $t$-tests were Bonferroni corrected.

\section{Wavelet-Analysis}

Evoked alpha-/beta- and gamma-activity were calculated using a complex Morlet wavelet transformation [see also (Herrmann et al., 1999; Mulert et al., 2007)]. The wavelet transformation was performed on averaged ERPs to reveal the phase-locked evoked fraction of the alpha-, beta-, and gamma-activity. As a first step, the frequency range from 1 to $60 \mathrm{~Hz}$ was divided into 40 frequency steps (distributed on a logarithmic scale) for each subject (Morlet parameter $c=5$; continuous wavelet transformation; Morlet complex wavelet). In the next step, for each participant separate parameters were calculated for alpha (frequency range $8.06-12.09 \mathrm{~Hz}$; mean: $10.08 \mathrm{~Hz}$ ), beta (frequency range $20.16-30.25 \mathrm{~Hz}$; mean: $25.21 \mathrm{~Hz}$ ), and gamma frequencies (frequency range $32.27-48.40 \mathrm{~Hz}$; mean: $40.34 \mathrm{~Hz}$; see also Karch et al., 2012).

Alpha/beta/gamma power was identified at $\mathrm{Fz}, \mathrm{Cz}$, and $\mathrm{Pz}$ in the time-frame $0-500 \mathrm{~ms}$ after the presentation of the second tone of each pair of tones. The length of the interval was adapted to the waveform of the oscillatory responses. Amplitudes were detected automatically using the Brain Vision Analyzer-Software Version 1.05 (see also Karch et al., 2012). ANOVAs were employed to test for differences between electrode position and task condition, as well as between paradigms (paradigm +/- vs. paradigm R/L).

\section{RESULTS}

\section{Behavioral Results}

The results are shown in Table 1. Mean response times were significantly longer in voluntary selection trials than in go trials in paradigm $+/-[F(1,13)=101.553 ; p<0.001]$ and paradigm $\mathrm{R} / \mathrm{L}[F(1,12)=31.321 ; p<0.001]$. The percentage of responses was significantly increased in the go compared to the voluntary selection condition in paradigm $+/-[F(1,13)=200.96$; $p<0.001]$ and in paradigm $\mathrm{R} / \mathrm{L}[F(1,12)=16.78 ; p=0.001]$. The error rate did not differ significantly between tasks $[F(1,12)=6.783 ; p=0.523]$.

The comparison of behavioral data of paradigm $+/-$ with those of paradigm $\mathrm{R} / \mathrm{L}$ revealed comparable reaction times $(p=0.273)$ and comparable percentages of correct responses $(p=0.543)$ during $g o$. In addition, the reaction time did not differ significantly during the voluntary selection task $(p=0.635)$. The percentage of responses was significantly higher in paradigm $\mathrm{R} / \mathrm{L}$ compared to paradigm $+/-(p<0.001)$. Participants used the left button in $53.7 \%$ of voluntary selection trials (reaction time: $M=861.6 \mathrm{~ms}$ ) and the right button in $45.4 \%$ of trials (reaction time: $M=840.3 \mathrm{~ms}$ ). Error rates were comparable in both groups $(p=0.122)$.

\section{Comparison of ERPs During go, Nogo, and Voluntary Selection Condition}

Results are shown in Figures 2 and 3.
TABLE 1 | Behavioral data: the response times were significantly longer in voluntary selection trials than in go trials in paradigm $+/-$ and paradigm R/L.

\begin{tabular}{|c|c|c|c|c|}
\hline & \multicolumn{2}{|c|}{ Paradigm $+/-$} & \multicolumn{2}{|c|}{ Paradigm $R / L$} \\
\hline & $M$ & $S D$ & $M$ & $S D$ \\
\hline \multicolumn{5}{|l|}{ Reaction time (ms) } \\
\hline Go & 516.0 & 116.93 & 568.7 & 127.49 \\
\hline Voluntary selection & 811.0 & 178.95 & 850.2 & 242.42 \\
\hline \multicolumn{5}{|l|}{ Percentage of responses (\%) } \\
\hline Go & 97.95 & 1.81 & 97.31 & 3.34 \\
\hline Voluntary selection & 56.34 & 10.63 & 94.38 & 3.18 \\
\hline \multicolumn{5}{|l|}{ Error rate $(\%)$} \\
\hline Responses during nogo or control & 3.74 & 2.41 & 2.23 & 2.50 \\
\hline
\end{tabular}

In addition, the percentage of responses was significantly increased in the go compared to the voluntary selection condition in both versions. The error rate did not differ significantly between tasks. M, Mean value; SD, standard deviation; $m s$, milliseconds; \%, percentage.

\section{Paradigm +/-}

N2

Regarding the $\mathrm{N} 2$-amplitude, in paradigm $+/-$ the main effect of condition (go, nogo, voluntary selection) $[F(2,26)=6.376$; $p=0.006]$ and the main effect of electrode position $(\mathrm{Fz}, \mathrm{Cz}, \mathrm{Pz})$ $[F(2,26)=4.922 ; p=0.034]$ turned out to be significant. The interaction between electrode position and experimental condition was not significant $[F(4,52)=1.918 ; p=0.162]$. Further analyses revealed that the N2 was significantly less pronounced in the go task compared to the voluntary selection condition $(p=0.015)$ as well as the nogo $(p=0.032)$. The N2 did not differ between voluntary selection and nogo $(p=1.0)$. When focusing on the localisation of the N2 (electrode position), the N2 was enhanced in Fz compared to $\mathrm{Cz}(p=0.010)$. The comparison of $\mathrm{Fz}$ and $\mathrm{Pz}$ $(p=0.280)$ as well as $\mathrm{Cz}$ and $\mathrm{Pz}(p=1.0)$ did not reveal significant differences.

\section{P3}

The results of the $\mathrm{P} 3$-amplitudes showed significant main effects of condition $[F(2,26)=23.267 ; p<0.001]$ and electrode position $[F(2,26)=3.437 ; p=0.047]$ as well as a significant interaction effect (condition $\times$ electrode position) $[F(4,52)=9.392 ; p<0.001]$. The P3 amplitude was increased in nogo trials compared to go trials $(p<0.001)$ and the voluntary selection condition $(p=0.008)$. Apart from this, voluntary selection associated P3 amplitudes were increased compared to those of the go task $(p=0.005)$. Regarding the position of the electrodes, there was a significantly increased $\mathrm{P} 3$ in $\mathrm{Cz}$ compared to $\mathrm{Fz}(p=0.020)$. The $\mathrm{P} 3$ in $\mathrm{Fz}$ and $\mathrm{Pz}$ $(p=1.0)$ as well as $\mathrm{Cz}$ and $\mathrm{Pz}(p=0.171)$ did not differ significantly.

Post hoc tests of the interaction effect revealed significant differences in $\mathrm{Fz}$ and $\mathrm{Cz}$ between go and nogo (Fz: $p=0.001$; $\mathrm{Cz}: p<0.001$ ), go and voluntary selection (Fz: $p=0.021 ; \mathrm{Cz}$ : $p=0.015)$ as well as nogo and voluntary selection (Fz: $p=0.035$; $\mathrm{Cz}: p=0.004$ ). The differences in $\mathrm{Pz}$ were not significant ( $g o$ vs. nogo: $p=0.385$; go vs. voluntary selection: $p=0.205$; nogo vs. voluntary selection: $p=1.000)$. 
Kerch et al.

RPs Associated to Intentional Actions

A

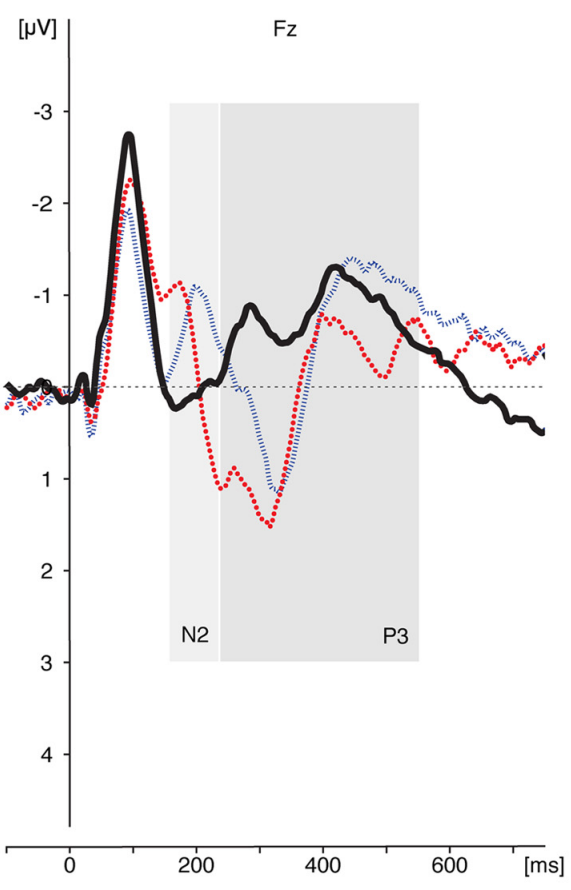

paradigm +/-

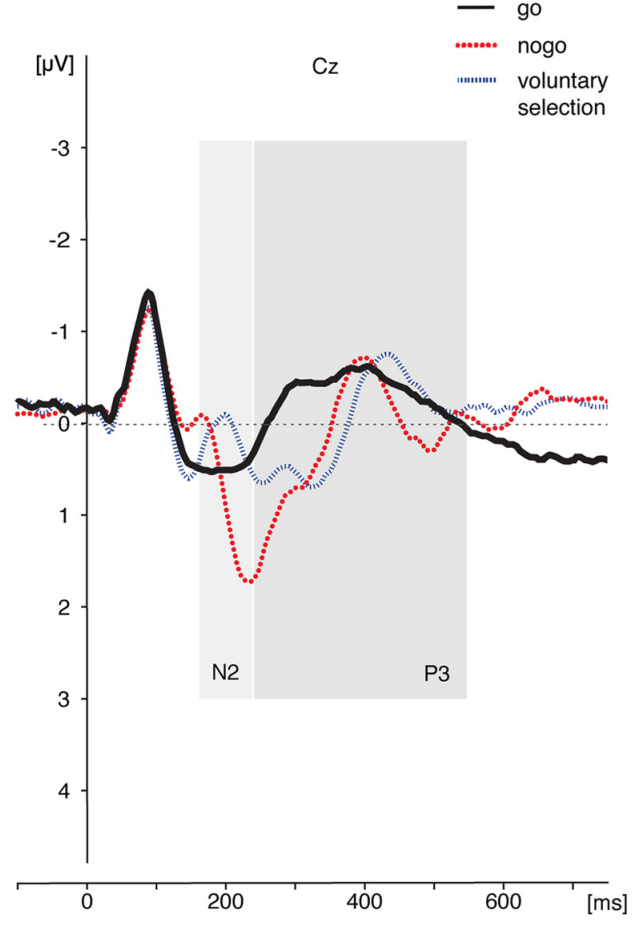

B

paradigm R/L
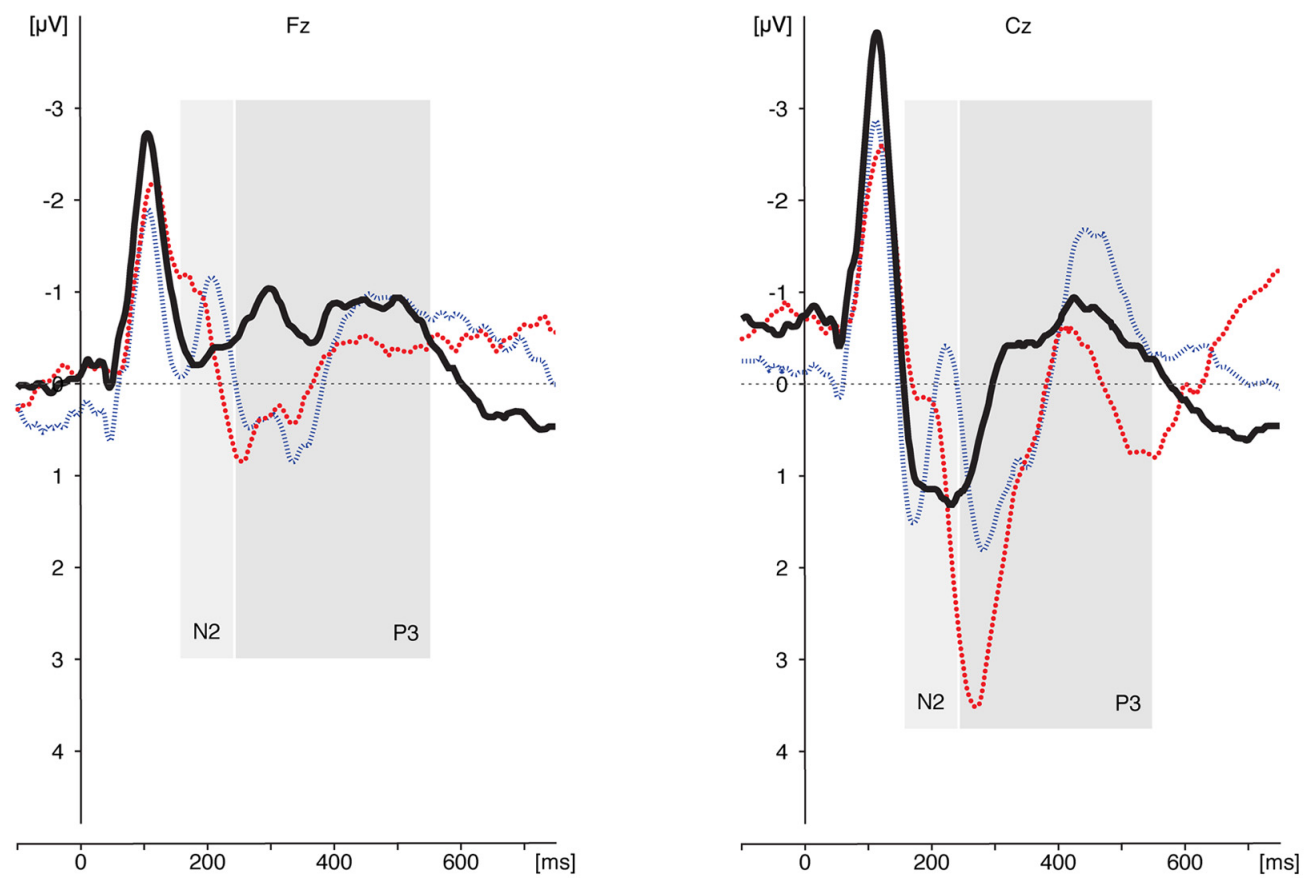

FIGURE 2 | Auditory evoked potentials of healthy controls. (A) ERRs concerning the paradigm +/-; (B) ERP results regarding the paradigm R/L. Subjects showed increased fronto-centrally located N2 amplitudes during the voluntary selection task and logo condition compared to go. The P3 amplitude was located in fronto-central brain areas during the nog condition and the voluntary selection condition. Abbreviations $\mu \mathrm{V}$, microvolt; ms, milliseconds.

Frontiers in Psychology | www.frontiersin.org

6

January 2016 | Volume 7 | Article 7 


\section{paradigm +/- vs. paradigm R/L}
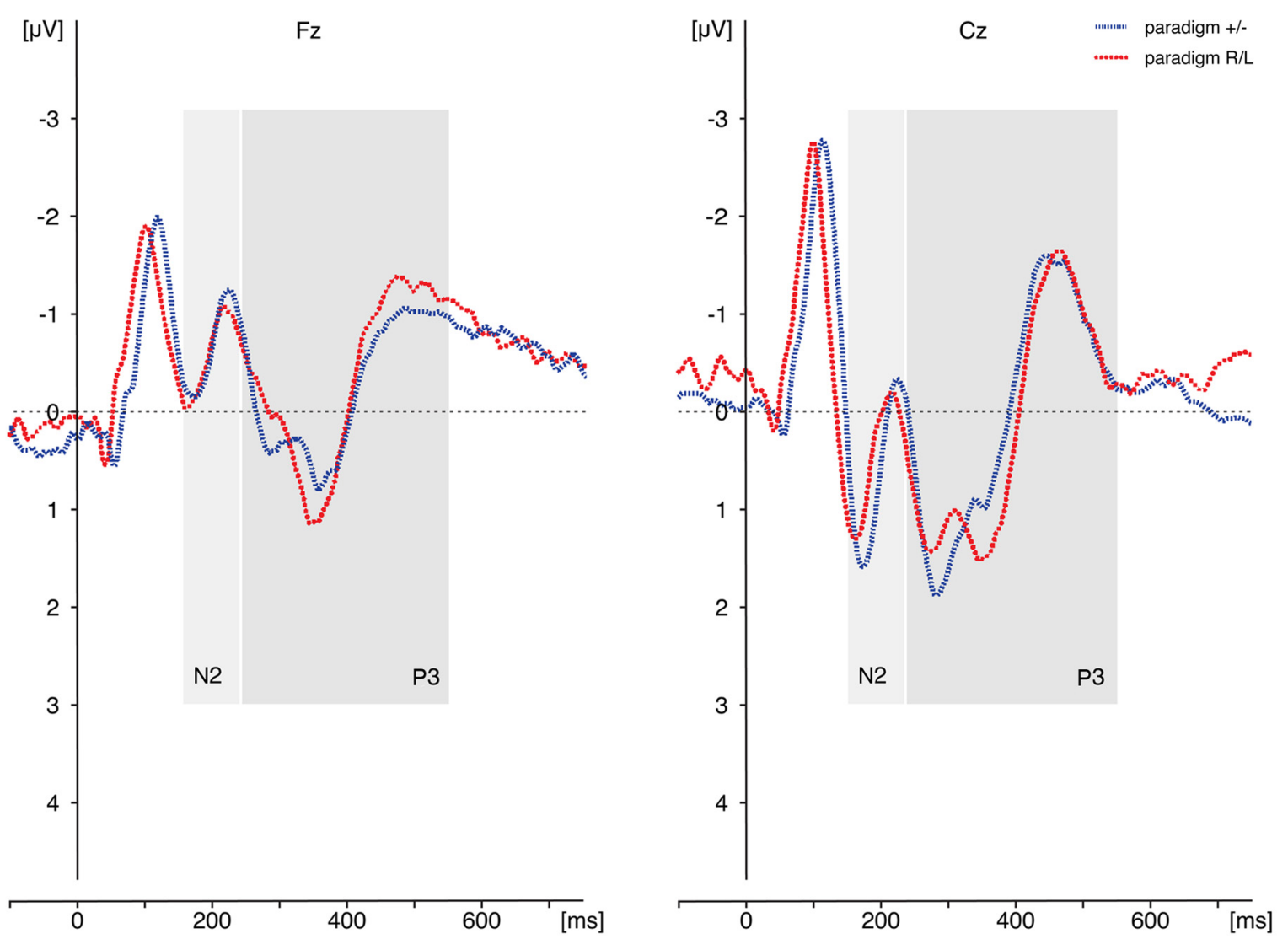

FIGURE 3 | Comparison of the voluntary selection-related responses during paradigm $+/-$ and paradigm R/L. The ERP results differed only marginally between paradigms. Abbreviations $\mu \mathrm{V}$, microvolt; ms, milliseconds.

\section{Paradigm R/L}

\section{N2}

The assessment of the N2 amplitude demonstrated that the main effects of condition $[F(2,24)=7.163 ; p=0.004]$ and electrode position $[F(2,24)=12.230 ; p<0.001]$ were statistically significant; the $\mathrm{N} 2$ amplitudes were more negatively in $\mathrm{Fz}$ compared to $\mathrm{Cz}(p<0.001)$ and $\mathrm{Pz}(p=0.008)$. The N2 did not differ between $\mathrm{Cz}$ and $\mathrm{Pz}(p=1.0)$. In addition, the $\mathrm{N} 2$ was less pronounced in go trials compared to nogo trials $(p=0.041)$ and voluntary selection trials $(p=0.041)$. The results of nogo and voluntary selection were comparable $(p=1.0)$. The interaction effect (condition $\times$ electrode position) was not significant $[F(4,48)=0.866 ; p=0.491]$.

\section{P3}

The P3-amplitudes differed significantly between conditions $[F(2,24)=11.218 ; p<0.001]$ and electrode positions $[F(2,24)=8.574 ; p=0.007]$. Apart from that, the interaction effect (condition $\times$ electrode position) was significant $[F(4,48)=6.001 ; p=0.004]$. Post hoc tests showed smaller P3 amplitudes in go compared to nogo $(p=0.008)$ and voluntary selection $(p=0.008)$; the P3 in nogo and voluntary selection was comparable $(p=0.152)$. Regarding the localisation, the P3 was decreased in $\mathrm{Fz}$ compared to $\mathrm{Cz}(p=0.005)$ and $\mathrm{Pz}(p=0.003)$; the difference between $\mathrm{Cz}$ and $\mathrm{Pz}$ was not significant $(p=0.602)$.

Post hoc tests of the interaction effect revealed significant differences in $\mathrm{Fz}$ and $\mathrm{Cz}$ between $g o$ and nogo (Fz: $p<0.001$; $\mathrm{Cz}: p=0.023$ ), go and voluntary selection (Fz: $p=0.006$; $\mathrm{Cz}$ : $p=0.023)$. The difference between nogo and voluntary selection was not significant for $\mathrm{Fz}(p=0.368)$ but $\mathrm{Cz}(p=0.045)$. The differences in $\mathrm{Pz}$ were not significant ( $g o$ vs. nogo: $p=1.000$; go vs. voluntary selection: $p=0.608$; nogo vs. voluntary selection: $p=1.000)$.

\section{Comparison of the Results of Paradigm $+/-$ and Paradigm R/L}

N2

The N2-amplitudes differed significantly between conditions $[F(2,50)=12.947 ; p<0.001]$ and electrode positions $[F(2,50)=12.997 ; p<0.001]$. The interaction effects condition $\times$ electrode position reached trend level $[F(4,100)=2.533 ; p=0.076]$. The interactions condition $\times$ group 
$[F(2,50)=0.181 ; p=0.835]$, electrode position $\times$ group $[F(2,50)=0.106 ; p=0.828]$ and condition $\times$ electrode position $\times$ group $[F(4,100)=0.190 ; p=0.868]$ were not statistically significant. The group effect (paradigm +/-; paradigm $\mathrm{R} / \mathrm{L}$ ) was not statistically significant $(p=0.921)$. Post hoc analysis revealed enhanced N2 amplitudes during nogo trials compared to go trials $(p=0.001)$ and in voluntary selection trials compared to go trials $(p=0.001)$, but no differences between nogo and voluntary selection $(p=1.0)$. With respect to the localisation of the N2 amplitudes, the results showed an increased $\mathrm{N} 2$ amplitude in Fz compared to $\mathrm{Cz}(p<0.001)$ and $\mathrm{Pz}(p=0.007)$ whereas the $\mathrm{N} 2$ in $\mathrm{Cz}$ and $\mathrm{Pz}$ did not differ significantly $(p=1.0)$.

\section{P3}

Regarding the P3-amplitude there were significant main effects of condition $[F(2,50)=32.524 ; p<0.001]$ and electrode position $[F(2,50)=10.831 ; p<0.001]$. In addition, the interaction condition $\times$ electrode position $[F(4,100)=14.495$; $p<0.001]$ was significant. By contrast, the interactions between condition $\times$ group $[F(2,50)=0.382 ; p=0.632]$, electrode position $\times$ group $[F(2,50)=2.239 ; p=0.117]$ and condition $\times$ electrode position $\times$ group $[F(4,100)=0.292$; $p=0.883$ ] were not significant. In addition, the groups did not differ significantly $[F(1,25)=0.010 ; p=0.921]$.

Post hoc $t$-tests indicated a significantly increased P3 amplitude during nogo trials compared to go trials $(p<0.001)$ and voluntary selection trials $(p=0.001)$. In addition, selectionrelated P3 amplitudes were increased compared to go-associated responses $(p<0.001)$. The P3 was increased in central areas compared to frontal regions $(\mathrm{Cz}>\mathrm{Fz} ; p<0.001)$; the difference between $\mathrm{Fz}$ and $\mathrm{Pz}(p=0.150)$ as well as $\mathrm{Cz}$ and $\mathrm{Pz}(p=0.082)$ was not significant.

Post hoc tests of the interaction effect revealed significant differences in $\mathrm{Fz}$ and $\mathrm{Cz}$ between $g o$ and nogo (Fz: $p<0.001$; $\mathrm{Cz}: p<0.001$ ), go and voluntary selection (Fz: $p<0.001 ; \mathrm{Cz}$ : $p=0.002)$ as well as nogo and voluntary selection (Fz: $p=0.009$; Cz: $p<0.001$ ). The differences in $\mathrm{Pz}$ were not significant ( $g o$ vs. nogo: $p=0.237$; go vs. voluntary selection: $p=0.077$; nogo vs. voluntary selection: $p=1.000$ ).

\section{Results of the Wavelet-Analysis}

The results of the wavelet-analysis are shown in Figure 4 and Table 2.

\section{Alpha Frequency Range}

Regarding alpha activity, responses related to paradigm $\mathrm{R} / \mathrm{L}$ did not differ significantly from those related to paradigm $+/-$ $[F(1,25)=0.120 ; p=0.732]$. The main effect of condition $[F(2,50)=6.538 ; p=0.003]$ was significant and demonstrated increased responses during voluntary selection compared to go $(p=0.005)$ but not between voluntary selection and nogo $(p=1.0)$ or nogo and go $(p=0.078)$.

The alpha response was significantly increased in the central area compared to frontal and parietal areas $(\mathrm{Cz}$ compared to $\mathrm{Fz}(p<0.001)$, and $\mathrm{Cz}$ compared to $\mathrm{Pz}(p<0.001)$ $[F(2,50)=25.477 ; p<0.001] ; \mathrm{Fz}$ compared to $\mathrm{Pz}$ did not differ significantly $(p=1.0)$. The interactions were not significant condition $\times$ group: $[F(2,50)=1.546 ; p=0.223]$; electrode position $\times$ group $[F(2,50)=0.365 ; p=0.696]$; elect rode position $\times$ condition: $[F(4,100)=1.938 ; p<0.110]$; condition $\times$ electrode position $\times$ group: $[F(4,100)=0.703$; $p=0.592]\}$.

Post hoc tests indicated increased alpha power during voluntary selection compared to go $(p=0.005)$; the results of voluntary selection and nogo $(p=1.0)$ and nogo and go $(p=0.078)$ did not differ.

\section{Beta-Frequency Range}

We did not find any difference in beta power between paradigm $+/-$ and paradigm $\mathrm{R} / \mathrm{L}[F(1,25)=1.401 ; p=0.248]$. The beta activity differed significantly between conditions $[F(2,50)=8.952$; $p<0.001]$ with increased responses during the voluntary selection condition compared to the go condition $(p<0.001)$ and compared to the nogo task $(p=0.031)$, but no differences between go and nogo $(p=0.857)$. In addition, there was a significant main effect of electrode position $[F(2,50)=6.666 ; p=0.003]$ with an increased activity in $\mathrm{Cz}$ compared to $\mathrm{Pz}(p=0.002)$ whereas the results of $\mathrm{Fz}$ and $\mathrm{Pz}(p=0.231)$ and $\mathrm{Fz}$ and $\mathrm{Cz}$ were comparable $(p=0.282)$.

All interactions were not significant [condition $\times$ group: $F(2,50)=0.688 ; p=0.507 ;$ electrode position $\times$ group: $F(2,50)=0.229 ; p=0.796 ;$ condition $\times$ electrode posi tion: $F(4,100)=0.403 ; p=0.806 ;$ condition $\times$ electrode position $\times$ group: $F(4,100)=0.917 ; p=0.457]$.

\section{Gamma Frequency Range}

Gamma power related to the paradigm $+/-$ and the paradigm $\mathrm{R} / \mathrm{L}$ did not differ significantly $[F(1,25)=0.741 ; p=0.398]$. However, the main effects of condition $[F(2,50)=10.492$; $p<0.001]$ and electrode position $[F(2,50)=11.378 ; p<0.001]$ as well as the interaction between condition and electrode position $[F(4,100)=5.232 ; p=0.001]$ were significant.

Gamma activity was more pronounced in voluntary selection trials compared to go trials $(p=0.001)$ and nogo trials $(p=0.002)$; gamma activity of $g o$ and nogo did not differ $(p=0.654)$. Gamma activity was especially located in frontal and frontocentral areas: differences between $\mathrm{Fz}$ and $\mathrm{Pz}(p<0.001)$ as well as $\mathrm{Cz}$ and $\mathrm{Pz}(p=0.013)$ associated gamma activity were significant. Differences between $\mathrm{Fz}$ and $\mathrm{Pz}$ were not significant $(p=1.0)$. The interaction effects condition $\times$ group $[F(2,50)=0.331$; $p=0.675]$, electrode position $\times$ group $[F(2,50)=0.591 ; p=0.557]$ and condition $\times$ electrode position $\times$ group $[F(6,306)=0.158$; $p=0.959]$ were not significant.

\section{DISCUSSION}

Intentional actions are supposed to be purposive and goaldirected as well as endogenously controlled (Brass and Haggard, 2008). In addition, attention is required in intentional actions and they offer a choice between alternatives (Jahanshahi, 1998). The aim of the present study was to distinguish electrophysiological correlates (ERPs; alpha, beta, gamma power) of intentional 


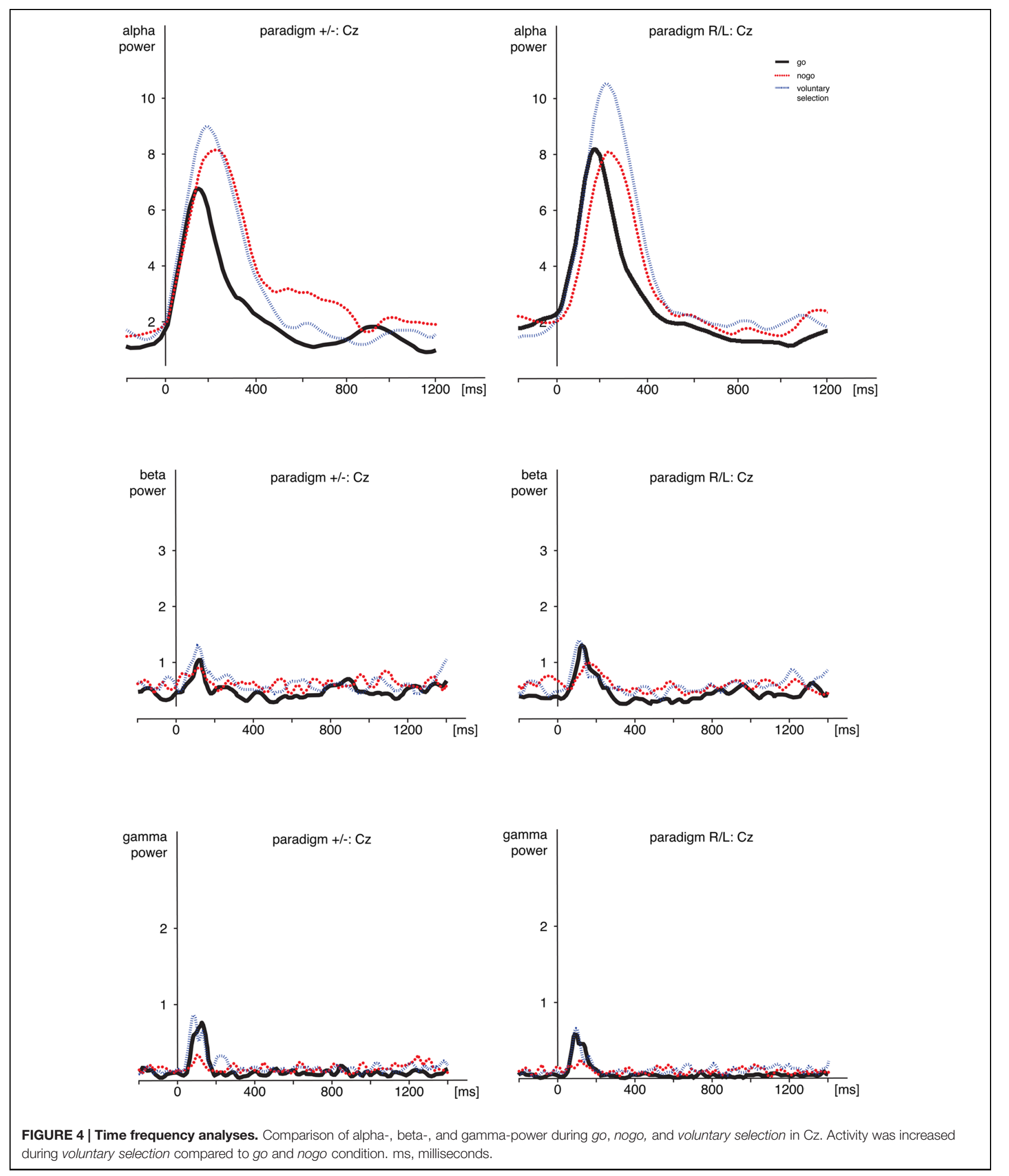

actions and externally guided actions. In addition, we compared neurobiological findings of different aspects of intentional actions: (1) "what" component comprising the decision, which action to perform; (2) "whether" component, which refers to the decision, whether or not to perform an action (Brass and Haggard, 2007, 2008). For that purpose, subjects were 
TABLE 2 | Wavelet analysis: mean value of alpha, beta, and gamma power during go, nogo, and voluntary selection in paradigm $+/-$ and paradigm R/L.

\begin{tabular}{|c|c|c|c|c|c|c|}
\hline & \multicolumn{3}{|c|}{ Paradigm +/- } & \multicolumn{3}{|c|}{ Paradigm R/L } \\
\hline & Fz & $\mathrm{Cz}$ & $\mathbf{P z}$ & $\mathbf{F z}$ & $\mathrm{Cz}$ & $\mathbf{P z}$ \\
\hline \multicolumn{7}{|l|}{ Alpha power } \\
\hline Go & 5.48 & 7.05 & 4.06 & 5.36 & 8.35 & 5.30 \\
\hline Nogo & 7.51 & 9.48 & 6.27 & 6.15 & 9.08 & 5.61 \\
\hline Voluntary selection & 5.80 & 9.64 & 6.53 & 6.68 & 10.75 & 6.54 \\
\hline \multicolumn{7}{|l|}{ Beta power } \\
\hline Go & 1.26 & 1.28 & 0.96 & 1.28 & 1.61 & 1.17 \\
\hline Nogo & 1.26 & 1.37 & 1.23 & 1.42 & 1.50 & 1.15 \\
\hline Voluntary selection & 1.39 & 1.57 & 1.29 & 1.49 & 1.65 & 1.41 \\
\hline \multicolumn{7}{|l|}{ Gamma power } \\
\hline Go & 1.06 & 1.23 & 0.31 & 0.74 & 0.91 & 0.35 \\
\hline Nogo & 0.88 & 0.62 & 0.49 & 0.72 & 0.53 & 0.50 \\
\hline Voluntary selection & 1.63 & 1.39 & 0.63 & 1.33 & 1.04 & 0.55 \\
\hline
\end{tabular}

instructed to decide voluntarily whether they wanted to respond by button press or not (paradigm +/-; "whether" component). Another experimental task included the decision to respond with their right or their left index finger (paradigm R/L; "what" component).

With regard to the behavioral data, we found increased reaction times associated with intentional actions (voluntary selection) compared to externally guided responses (go). These findings are in line with the results of earlier studies using the same paradigm (Karch et al., 2009, 2010b). In addition, the responses of the participants during voluntary selection were carefully monitored by the instructor in order to prevent that the responses were systematically (e.g., alternating response and no response). Taking this information together may indicate that an additional cognitive process is essential for the processing of intentional responses compared to stimulus-driven actions. Reaction times did not differ, irrespective of the kind of intentional process (decision what to do or whether to respond or not).

In the present study, intentional processes were associated with a fronto-centrally located $\mathrm{N} 2$ and $\mathrm{P} 3$ potential. The N2 and P3 amplitude were increased during voluntary selection processes compared to instructed responses ( $g o$ ). The findings of some former studies regarding voluntary selection are similar to those of the present study (Karch et al., 2009, 2010a,b). By contrast, the results of Waszak et al. (2005) regarding electrophysiological correlates of intentional and stimulus-based actions differ considerably from the findings of the present study. Their results demonstrated that electrophysiological responses occurred much earlier in the intention-based condition compared to the stimulus-based condition. The response-locked lateralised readiness potential remained relatively invariant between conditions. The authors assumed that the results provide evidence for two different modes of action selection: one mode seems to be stimulus-driven, the other seems to be mainly intention-driven (Waszak et al., 2005). The differences between the results of the present study and the study of Waszak et al. (2005) could be influenced by differences regarding the experimental paradigm.

Information about the functional meaning of the N2 and P3 is inconsistent: there is some evidence that the N2 is associated with the selection of a response and influences subsequent stages of processing reflected in the $\mathrm{P} 3$. Unexpected revisions of the response program seemed to delay and enhance the N2 (Gajewski et al., 2008). Forstmann et al. (2007) suggested that the choicerelated N2-P2 complex might reflect early sensory-perceptual processing, whereas the $\mathrm{P} 3$ is associated with the evaluation of the stimulus (Forstmann et al., 2007). The authors assumed that a choice between several task sets invokes medial frontal activity. Apart from that, a number of other brain regions seemed to be relevant for choices including parieto-occipital areas (Forstmann et al., 2007).

The ability to localize generators of ERP components is limited because of the low spatial resolution of EEG recordings. The results of a simultaneous EEG and functional MRI study using the voluntary selection paradigm showed that N2-related neuronal responses were mainly associated with medial and lateral parts of the frontal cortex. By contrast, the P3 was predominantly related to enhanced neuronal responses in lateral frontal brain areas and the temporo-parietal junction (Karch et al., 2010a). This may indicate that the frontal cortex is involved at an earlier stage than temporal and -parietal regions (Karch et al., 2010a).

Medial frontal areas, including the rostral cingulate zone, have already shown to be involved in the control of voluntary behavior as well as conflict monitoring, error detection and decision making (Jenkins et al., 2000; Botvinick et al., 2001; Garavan et al., 2002; Lau et al., 2004b, 2006; Nachev et al., 2005; Forstmann et al., 2006; Karch et al., 2009). These concepts might be partly overlapping: Krieghoff et al. (2011), for example, suggested that response conflict and volition represent two sides of the same coin and that there is no will without "conflicting" ideas (Krieghoff et al., 2011).

N2 and P3 amplitudes were not only detected during intentional actions but also during response inhibition. The N2 amplitude during nogo and voluntary selection did not differ significantly. By contrast, fronto-central P3 amplitudes were increased during response inhibition compared to both voluntary behavior and stimulus-dependent responses. Our findings of pronounced nogo N3 and P3 potentials are in line with former studies: response inhibition processes were frequently associated with a fronto-centrally located N2 potential and P3 potential (Pfefferbaum et al., 1985; Kopp et al., 1996; Bruin et al., 2001; Donkers and van Boxtel, 2004; Smith et al., 2004; Bekker et al., 2005). The nogo N2 appeared to be located in medial frontal regions (Bekker et al., 2005). It is assumed that the N2 is relevant for the suppression of incorrect response tendencies (Falkenstein et al., 1999) and could be associated with the rare presentation of stimuli (Donkers and van Boxtel, 2004; Bartholow et al., 2005), or is linked to stimulus classification (Ritter et al., 1983) as well as conflict (Randall and Smith, 2011). The frontally located P3 seemed to be more clearly associated with response inhibition and could be an indicator of both cognitive and motor inhibition (Smith et al., 2008), alternatively it reflects the cancelation of a planned response (Randall and Smith, 2011). 
Concerning oscillatory responses, we detected increased alpha, beta, and gamma activity during intentional actions compared to instructed responses ( $g o$ ). Apart from that, betaand gamma-power were more pronounced during voluntary responses compared to the inhibition of behavioral responses. Increased oscillatory activity was predominantly located in frontal and fronto-central areas. These results may indicate that oscillatory responses might be more helpful to further distinguish functional correlates of voluntary responses and response inhibition.

In general, there is a broad consensus that different kinds of oscillation denote different brain activity states and that oscillatory fluctuations across time are representative of the dynamic interplay between different cell types in various cortical and subcortical circuits (Buzsaki, 2006). The application of sensory or cognitive stimuli influences these responses. Oscillatory phenomena are strongly interwoven with sensory and cognitive functions: oscillatory processes could play a major role in relation to memory and integrative functions (Basar et al., 2000).

Especially gamma-band synchronization has attracted considerable interest over recent years because mechanistic roles have been proposed in phase coding, perceptual integration, and flexible routing of information in the visual system (Fries, 2009; Vinck et al., 2013), and furthermore because of its appearance in multiple cortical and subcortical structures (Fries, 2009). Former studies have demonstrated that oscillations in higher frequency ranges, especially gamma activity, are influenced by a various cognitive processes including object recognition, attention and working memory as well as the preparation of motor responses (Tiitinen et al., 1993; Yordanova et al., 1997; Engel et al., 2001; Debener et al., 2003; Basar-Eroglu et al., 2007). In addition, gamma activity increases with increasing task difficulty (Senkowski and Herrmann, 2002; Posada et al., 2003; Mulert et al., 2007). Midline areas, especially the dorsal part of the ACC and the medial frontal cortex, are assumed to be related to gamma-band responses (Mulert et al., 2007). These processes are assumed to be influenced by inhibitory interneurons and pyramidal cells (Bartos et al., 2007; Cardin et al., 2009; Sohal et al., 2009). Bosman et al. (2014) assumed that gamma band activity originates from the interplay between inhibition and excitation. Overall, gamma band oscillations support multiple cognitive processes rather than a single one. At a higher functional level, gamma-band oscillations seem to be influenced by visual attention, decision-making, response timing, motivation and short- and long-term memory (Bosman et al., 2014). They coordinate neuronal activity in hippocampal and neocortical networks (Kann et al., 2014). Cortico-cortical communication and the large scale integration of disturbed sets of neurons are needed for a well functioning cognitive ability and require synchronous neural gamma oscillations (Rodriguez et al., 1999).

EEG oscillations in the alpha and theta band reflect cognitive and memory performance (Klimesch, 1999). In addition, alpha band responses have been associated with working memory (Schack and Klimesch, 2002; Busch and Herrmann, 2003; Klimesch et al., 2005). Alpha activity was shown to grow with increasing memory load (Klimesch et al., 2005). Thalamo-cortical circuits as well as hippocampal areas are supposed to be relevant for the generation of alpha responses (Basar, 1998, 1999).

In addition, a recent review provides evidence that theta band activities over the mid-frontal cortex seem to reflect a common computation used for realizing the need for cognitive control (Cavanagh and Frank, 2014). Theta band processes may be used to communicate this need and subsequently implement such control across disparate brain regions. Thus, frontal theta is a compelling candidate mechanism by which emergent processes, such as 'cognitive control', may be biophysically realized (Cavanagh and Frank, 2014).

The results of the present study are in line with the assumptions concerning the function of alpha, beta, and gamma oscillations: intentional responses might require pronounced cognitive process including cognitive control mechanisms as well as higher cognitive processes including decision-making in order to be effective. Overall, the results provide evidence that intentional actions might be more complex and seem to be related to cognitive control compared to instructed responses as well as response inhibition.

Intention-related variations in the alpha, beta, and/or gamma band activity seem to be measurable with the paradigm. This may provide the possibility to determine functional variations that are related with intentional actions in various neuropsychiatric disorders, e.g., in patients with ADHD or schizophrenia. It has been suggested that impairments regarding brain oscillations reflect disturbed information processing and a disruption in normal neuronal synchronization, e.g., caused by dysfunctional GABA/glutamate system, may contribute to deficits in cognitive and affective integration (Ozerdem et al., 2010). Basar et al. (2015) assume that oscillatory activity obtained by various input modalities are capable of displaying the relationship between any given neuropsychiatric disturbance and different neurotransmitter systems. In addition, brain oscillations may also show plasticity or compensation (Basar et al., 2015): a decrease in one frequency range may occur in parallel with the increase in a different frequency range.

In future, differences regarding intention-related neuronal responses between different neuropsychiatric disorders as well as the effect of psychotherapeutic interventions and pharmacological treatment on intention-related neuronal processes may be determined.

Another important aspect of the present study was a dissociation of neural correlates of different aspects of intentional actions. We did not find reliable differences regarding both ERPs and oscillatory responses: alpha-, beta-, and gamma-activity did not differ significantly between "whether" and "what" decisions. In addition, the N2 and P3 amplitudes were comparable. These results are somewhat surprising. However, up to now only a few studies exist that focus on this topic. Krieghoff et al. (2009) showed that the rostral cingulate zone is involved in the decision of which action to perform. By contrast, a part of the superior frontal gyrus in the paramedian frontal cortex seemed to be involved in the decision of "when" to perform action (Krieghoff et al., 2009). Brass and Haggard (2007) examined neural aspects of the "whether" component: in their study subjects were instructed 
to cancel an intended response at the last possible moment. Functional MRI results demonstrated the involvement of the dorsal fronto-median cortex (Brass and Haggard, 2007). To our knowledge, "what" and "whether" decisions have not been compared directly so far. In addition, these studies focused on functional differences concerning the localisation of the functional correlates of decisions. Differences regarding the localisation were not examined in the present study because of the low spatial resolution of electrophysiological responses. By contrast, differences regarding the functional meaning of the processes involved were addressed.

Altogether, the results of the present study indicate that intentional actions are related to fronto-centrally located $\mathrm{N} 2$ and P3 potentials. These responses seemed to be more pronounced than those related to instructed responses and the instructed inhibition of responses. In addition, alpha-, beta-, and gamma-band responses were increased during the

\section{REFERENCES}

Bartholow, B. D., Pearson, M. A., Dickter, C. L., Sher, K. J., Fabiani, M., and Gratton, G. (2005). Strategic control and medial frontal negativity: beyond errors and response conflict. Psychophysiology 42, 33-42. doi: 10.1111/j.14698986.2005.00258.x

Bartos, M., Vida, I., and Jonas, P. (2007). Synaptic mechanisms of synchronized gamma oscillations in inhibitory interneuron networks. Nat. Rev. Neurosci. 8, 45-56. doi: 10.1038/nrn2044

Basar, E. (1998). Brain Function and Oscillations I. Brain Oscillations: Principles and Approaches. Heidelberg: Springer.

Basar, E. (1999). Brain Functiona nd Oscillations II. Integrative Brain Function. Neurophysiology and Cognitive Processes. Heidelberg: Springer.

Basar, E., Basar-Eroglu, C., Karakas, S., and Schurmann, M. (2000). Brain oscillations in perception and memory. Int. J. Psychophysiol. 35, 95-124. doi: 10.1016/S0167-8760(99)00047-1

Basar, E., Schmiedt-Fehr, C., Mathes, B., Femir, B., Emek-Savas, D. D., Tülay, E., et al. (2015). What does the broken brain say to the neuroscientist? Oscillations and connectivity in schizophrenia, Alzheimer's disease, and bipolar disorder. Int. J. Psychophysiol. doi: 10.1016/j.ijpsycho.2015.02.004 [Epub ahead of print].

Basar-Eroglu, C., Brand, A., Hildebrandt, H., Karolina Kedzior, K., Mathes, B., and Schmiedt, C. (2007). Working memory related gamma oscillations in schizophrenia patients. Int. J. Psychophysiol. 64, 39-45. doi: 10.1016/j.ijpsycho.2006.07.007

Beck, A. T., and Steer, R. A. (1987). Beck Depression Inventory - Manual. San Antonio: The Psychological Association.

Bekker, E. M., Kenemans, J. L., and Verbaten, M. N. (2004). Electrophysiological correlates of attention, inhibition, sensitivity and bias in a continuous performance task. Clin. Neurophysiol. 115, 2001-2013. doi: 10.1016/j.clinph.2004.04.008

Bekker, E. M., Kenemans, J. L., and Verbaten, M. N. (2005). Source analysis of the N2 in a cued Go/NoGo task. Brain Res. Cogn. Brain Res. 22, 221-231. doi: 10.1016/j.cogbrainres.2004.08.011

Bosman, C. A., Lansink, C. S., and Pennartz, C. M. (2014). Functions of gammaband synchronization in cognition: from single circuits to functional diversity across cortical and subcortical systems. Eur. J. Neurosci. 39, 1982-1999. doi: 10.1111/ejn.12606

Botvinick, M. M., Braver, T. S., Barch, D. M., Carter, C. S., and Cohen, J. D. (2001). Conflict monitoring and cognitive control. Psychol. Rev. 108, 624-652. doi: 10.1037/0033-295X.108.3.624

Brass, M., and Haggard, P. (2007). To do or not to do: the neural signature of self-control. J. Neurosci. 27, 9141-9145. doi: 10.1523/JNEUROSCI.092407.2007

Brass, M., and Haggard, P. (2008). The what, when, whether model of intentional action. Neuroscientist 14, 319-325. doi: 10.1177/1073858408317417 voluntary selection between response alternatives, compared to instructed responses. These results suggest that an additional cognitive process is needed for intentional actions compared to instructed behavior. The neural responses were comparatively independent of the kind of decision that was made.

\section{ACKNOWLEDGMENTS}

SK and FL contributed equally to this study. Parts of this work were prepared in the context of the MD thesis of SS and FL at the Faculty of Medicine, Ludwig-Maximilians-University, Munich. We thank Mije Hartmann who assisted with the proof-reading of the manuscript. Furthermore, we thank Julian Grassl, Irmgard Hantschk, and Josef Christan who assisted in the preparation of the figures.

Bruin, K. J., Wijers, A. A., and Van Staveren, A. S. (2001). Response priming in a go/nogo task: do we have to explain the go/nogo N2 effect in terms of response activation instead of inhibition? Clin. Neurophysiol. 112, 1660-1671. doi: 10.1016/S1388-2457(01)00601-0

Busch, N. A., and Herrmann, C. S. (2003). Object-load and feature-load modulate EEG in a short-term memory task. Neuroreport 14, 1721-1724. doi: 10.1097/00001756-200309150-00013

Buzsaki, G. (2002). Theta oscillations in the hippocampus. Neuron 33, 325-340. doi: 10.1016/S0896-6273(02)00586-X

Buzsaki, G. (2006). Rhythms of the Brain. New York, NY: Oxford University Press. Cardin, J. A., Carlen, M., Meletis, K., Knoblich, U., Zhang, F., Deisseroth, K., et al. (2009). Driving fast-spiking cells induces gamma rhythm and controls sensory responses. Nature 459, 663-667. doi: 10.1038/nature08002

Cavanagh, J. F., and Frank, M. J. (2014). Frontal theta as a mechanism for cognitive control. Trends Cogn. Sci. 18, 414-421. doi: 10.1016/j.tics.2014. 04.012

Cunnington, R., Windischberger, C., Deecke, L., and Moser, E. (2003). The preparation and readiness for voluntary movement: a high-field event-related fMRI study of the Bereitschafts-BOLD response. Neuroimage 20, 404-412. doi: 10.1016/S1053-8119(03)00291-X

Debener, S., Herrmann, C. S., Kranczioch, C., Gembris, D., and Engel, A. K. (2003). Top-down attentional processing enhances auditory evoked gamma band activity. Neuroreport 14, 683-686. doi: 10.1097/00001756-20030415000005

Deldin, P. J., Duncan, C. C., and Miller, G. A. (1994). Season, gender, and P300. Biol. Psychol. 39, 15-28. doi: 10.1016/0301-0511(94)90054-X

Donchin, E., and Coles, M. G. H. (1988). Is the P300 component a manifestation of context updating? Behav. Brain Sci. 11, 355-372. doi: 10.1017/S0140525X00058027

Donkers, F. C., and van Boxtel, G. J. (2004). The N2 in go/no-go tasks reflects conflict monitoring not response inhibition. Brain Cogn. 56, 165-176. doi: 10.1016/j.bandc.2004.04.005

Engel, A. K., Fries, P., and Singer, W. (2001). Dynamic predictions: oscillations and synchrony in top-down processing. Nat. Rev. Neurosci. 2, 704-716. doi: $10.1038 / 35094565$

Falkenstein, M., Hoormann, J., and Hohnsbein, J. (1999). ERP components in Go/Nogo tasks and their relation to inhibition. Acta Psychol. (Amst) 101, 267-291. doi: 10.1016/S0001-6918(99)00008-6

Forstmann, B. U., Brass, M., Koch, I., and Von Cramon, D. Y. (2006). Voluntary selection of task sets revealed by functional magnetic resonance imaging. J. Cogn. Neurosci. 18, 388-398. doi: 10.1162/jocn.2006.18.3.388

Forstmann, B. U., Ridderinkhof, K. R., Kaiser, J., and Bledowski, C. (2007). At your own peril: an ERP study of voluntary task set selection processes in the medial frontal cortex. Cogn. Affect. Behav. Neurosci. 7, 286-296. doi: 10.3758/CABN.7.4.286 
Fries, P. (2009). Neuronal gamma-band synchronization as a fundamental process in cortical computation. Annu. Rev. Neurosci. 32, 209-224. doi: 10.1146/annurev.neuro.051508.135603

Frith, C. D., Friston, K., Liddle, P. F., and Frackowiak, R. S. (1991). Willed action and the prefrontal cortex in man: a study with PET. Proc. Biol. Sci. 244, 241-246. doi: 10.1098/rspb.1991.0077

Gajewski, P. D., Stoerig, P., and Falkenstein, M. (2008). ERP-correlates of response selection in a response conflict paradigm. Brain Res. 1189, 127-134. doi: 10.1016/j.brainres.2007.10.076

Garavan, H., Ross, T. J., Murphy, K., Roche, R. A., and Stein, E. A. (2002). Dissociable executive functions in the dynamic control of behavior: inhibition, error detection, and correction. Neuroimage 17, 1820-1829. doi: 10.1006/nimg.2002.1326

Happé, F., Booth, R., Charlton, R., and Hughes, C. (2006). Executive function deficits in Autism spectrum disorders and attention-deficit/hyperactivity disorder: examining profiles across domains and ages. Brain Cogn. 61, 25-39. doi: 10.1016/j.bandc.2006.03.004

Herrmann, C. S., and Demiralp, T. (2005). Human EEG gamma oscillations in neuropsychiatric disorders. Clin. Neurophysiol. 116, 2719-2733. doi: 10.1016/j.clinph.2005.07.007

Herrmann, C. S., Mecklinger, A., and Pfeifer, E. (1999). Gamma responses and ERPs in a visual classification task. Clin. Neurophysiol. 110, 636-642. doi: 10.1016/S1388-2457(99)00002-4

Herrmann, C. S., Senkowski, D., and Rottger, S. (2004). Phase-locking and amplitude modulations of EEG alpha: two measures reflect different cognitive processes in a working memory task. Exp. Psychol. 51, 311-318. doi: 10.1027/1618-3169.51.4.311

Hosenbocus, S., and Chahal, R. (2012). A review of executive function deficits and pharmacological management in children and adolescents. J. Can. Acad. Child. Adolesc. Psychiatry 21, 223-229.

Hyder, F., Phelps, E. A., Wiggins, C. J., Labar, K. S., Blamire, A. M., and Shulman, R. G. (1997). "Willed action": a functional MRI study of the human prefrontal cortex during a sensorimotor task. Proc. Natl. Acad. Sci. U.S.A. 94, 6989-6994. doi: 10.1073/pnas.94.13.6989

Jahanshahi, M. (1998). Willed action and its impairments. Cogn. Neuropsychol. 15, 483-533. doi: 10.1080/026432998381005

Jenkins, I. H., Jahanshahi, M., Jueptner, M., Passingham, R. E., and Brooks, D. J. (2000). Self-initiated versus externally triggered movements. II. The effect of movement predictability on regional cerebral blood flow. Brain 123(Pt 6), 1216-1228. doi: 10.1093/brain/123.6.1216

Jueptner, M., Stephan, K. M., Frith, C. D., Brooks, D. J., Frackowiak, R. S., and Passingham, R. E. (1997). Anatomy of motor learning. I. Frontal cortex and attention to action. J. Neurophysiol. 77, 1313-1324.

Kann, O., Papageorgiou, I. E., and Draguhn, A. (2014). Highly energized inhibitory interneurons are a central element for information processing in cortical networks. J. Cereb. Blood Flow Metab. 34, 1270-1282. doi: 10.1038/jcbfm.2014.104

Karch, S., Feuerecker, R., Leicht, G., Meindl, T., Hantschk, I., Kirsch, V., et al. (2010a). Separating distinct aspects of the voluntary selection between response alternatives: $\mathrm{N}_{2}$ - and P3-related BOLD responses. Neuroimage 51, 356-364. doi: 10.1016/j.neuroimage.2010.02.028

Karch, S., Thalmeier, T., Lutz, J., Cerovecki, A., Opgen-Rhein, M., Hock, B., et al. (2010b). Neural correlates (ERP/fMRI) of voluntary selection in adult ADHD patients. Eur. Arch. Psychiatry Clin. Neurosci. 260, 427-440. doi: 10.1007/s00406-009-0089-y

Karch, S., Mulert, C., Thalmeier, T., Lutz, J., Leicht, G., Meindl, T., et al. (2009). The free choice whether or not to respond after stimulus presentation. Hum. Brain Mapp. 30, 2971-2985. doi: 10.1002/hbm.20722

Karch, S., Segmiller, F., Hantschk, I., Cerovecki, A., Opgen-Rhein, M., Hock, B., et al. (2012). Increased gamma oscillations during voluntary selection processes in adult patients with attention deficit/hyperactivity disorder. J. Psychiatr. Res. 46, 151-223. doi: 10.1016/j.jpsychires.2012. 07.017

Klimesch, W. (1999). EEG alpha and theta oscillations reflect cognitive and memory performance: a review and analysis. Brain Res. Brain Res. Rev. 29, 169-195. doi: 10.1016/S0165-0173(98)00056-3

Klimesch, W., Doppelmayr, M., Yonelinas, A., Kroll, N. E., Lazzara, M., Rohm, D., et al. (2001). Theta synchronization during episodic retrieval: neural correlates of conscious awareness. Brain Res. Cogn. Brain Res. 12, 33-38. doi: 10.1016/S0926-6410(01)00024-6

Klimesch, W., Schack, B., and Sauseng, P. (2005). The functional significance of theta and upper alpha oscillations. Exp. Psychol. 52, 99-108. doi: 10.1027/16183169.52.2.99

Kopp, B., Mattler, U., Goertz, R., and Rist, F. (1996). N2, P3 and the lateralized readiness potential in a nogo task involving selective response priming. Electroencephalogr. Clin. Neurophysiol. 99, 19-27. doi: 10.1016/0921$884 X(96) 95617-9$

Kramer, A. F., and Strayer, D. L. (1988). Assessing the development of automatic processing: an application of dual-task and event-related brain potential methodologies. Biol. Psychol. 26, 231-267. doi: 10.1016/0301-0511(88) 90022-1

Krieghoff, V., Brass, M., Prinz, W., and Waszak, F. (2009). Dissociating what and when of intentional actions. Front. Hum. Neurosci. 3:3. doi: 10.3389/neuro.09.003.2009

Krieghoff, V., Waszak, F., Prinz, W., and Brass, M. (2011). Neural and behavioral correlates of intentional actions. Neuropsychologia 49, 767-776. doi: 10.1016/j.neuropsychologia.2011.01.025

Lau, H. C., Rogers, R. D., Haggard, P., and Passingham, R. E. (2004a). Attention to intention. Science 303, 1208-1210. doi: 10.1126/science. 1090973

Lau, H. C., Rogers, R. D., Ramnani, N., and Passingham, R. E. (2004b). Willed action and attention to the selection of action. Neuroimage 21, 1407-1415. doi: 10.1016/j.neuroimage.2003.10.034

Lau, H., Rogers, R. D., and Passingham, R. E. (2006). Dissociating response selection and conflict in the medial frontal surface. Neuroimage 29, 446-451. doi: 10.1016/j.neuroimage.2005.07.050

Leicht, G., Andreou, C., Polomac, N., Lanig, C., Schöttle, D., Lambert, M., et al. (2015). Reduced auditory evoked gamma band response and cognitive processing deficits in first episode schizophrenia. World J. Biol. Psychiatry 16, 1-11. doi: 10.3109/15622975.2015.1017605

Leicht, G., Kirsch, V., Giegling, I., Karch, S., Hantschk, I., Moller, H. J., et al. (2010). Reduced early auditory evoked gamma-band response in patients with schizophrenia. Biol. Psychiatry 67, 224-231. doi: 10.1016/j.biopsych.2009.07.033

Leicht, G., Vauth, S., Polomac, N., Andreou, C., Rauh, J., Mußmann, M., et al. (2016). EEG-Informed fMRI Reveals a disturbed gamma-band-specific network in subjects at high risk for psychosis. Schizophr. Bull. 42, 239-249. doi: $10.1093 /$ schbul/sbv092

Makeig, S. (1993). Auditory event-related dynamics of the EEG spectrum and effects of exposure to tones. Electroencephalogr. Clin. Neurophysiol. 86, 283-293. doi: 10.1016/0013-4694(93)90110-H

Mulert, C., Leicht, G., Pogarell, O., Mergl, R., Karch, S., Juckel, G., et al. (2007). Auditory cortex and anterior cingulate cortex sources of the early evoked gamma-band response: relationship to task difficulty and mental effort. Neuropsychologia 45, 2294-2306. doi: 10.1016/j.neuropsychologia.2007.02.020

Näätänen, R., and Picton, T. W. (1986). N2 and automatic versus controlled processes. Electroencephalogr. Clin. Neurophysiol. Suppl. 38, 169-186.

Nachev, P., Rees, G., Parton, A., Kennard, C., and Husain, M. (2005). Volition and conflict in human medial frontal cortex. Curr. Biol. 15, 122-128. doi: 10.1016/j.cub.2005.01.006

Nachev, P., Wydell, H., O'neill, K., Husain, M., and Kennard, C. (2007). The role of the pre-supplementary motor area in the control of action. Neuroimage 36(Suppl. 2), T155-T163. doi: 10.1016/j.neuroimage.2007.03.034

Ozerdem, A., Güntekin, B., Saarci, E., Tunca, Z., and Basar, E. (2010). Disturbance in long distance gamma coherence in bipolar disorder. Prog. Neuropsychopharmacol. Biol. Psychiatry 34, 861-865. doi: 10.1016/j.pnpbp.2010.04.001

Ozonoff, S., Cook, I., Coon, H., Dawson, G., Joseph, R., Klin, A., et al. (2004). Performance on cambridge neuropsychological test automated battery subtests sensitive to frontal lobe function in people with autistic disorder: evidence from the collaborative programs of excellence in autism network. J. Autism. Dev. Disord. 34, 139-150. doi: 10.1023/B:JADD.0000022605.81989.cc

Pfefferbaum, A., Ford, J. M., Weller, B. J., and Kopell, B. S. (1985). ERPs to response production and inhibition. Electroencephalogr. Clin. Neurophysiol. 60, 423-434. doi: 10.1016/0013-4694(85)91017-X

Polich, J., and Kok, A. (1995). Cognitive and biological determinants of P300: an integrative review. Biol. Psychol. 41, 103-146. doi: 10.1016/03010511(95)05130-9 
Posada, A., Hugues, E., Franck, N., Vianin, P., and Kilner, J. (2003). Augmentation of induced visual gamma activity by increased task complexity. Eur. J. Neurosci. 18, 2351-2356. doi: 10.1046/j.1460-9568.2003.02962.x

Randall, W. M., and Smith, J. L. (2011). Conflict and inhibition in the cued-Go/NoGo task. Clin. Neurophysiol. 122, 2400-2407. doi: 10.1016/j.clinph.2011.05.012

Ridderinkhof, K. R., Ullsperger, M., Crone, E. A., and Nieuwenhuis, S. (2004). The role of the medial frontal cortex in cognitive control. Science 306, 443-447. doi: 10.1126/science. 1100301

Ritter, W., Simson, R., and Vaughan, H. G. Jr. (1983). Event-related potential correlates of two stages of information processing in physical and semantic discrimination tasks. Psychophysiology 20, 168-179. doi: 10.1111/j.14698986.1983.tb03283.x

Robinson, S., Goddard, L., Dritschel, B., Wisley, M., and Howlin, P. (2009). Executive functions in children with Autism Spectrum Disorders. Brain Cogn. 71, 362-368. doi: 10.1016/j.bandc.2009.06.007

Rodriguez, E., George, N., Lachaux, J. P., Martinerie, J., Renault, B., and Varela, F. J. (1999). Perception's shadow: long-distance synchronization of human brain activity. Nature 397, 430-433. doi: 10.1038/17120

Royall, D., Lauterbach, E., Cummings, J., Reeve, A., Rummans, T., Kaufer, D., et al. (2002). Executive control function: a review of its promise and challenges for clinical research. A report from the committee on research of the American Neuropsychiatric Association. J. Neuropsychiatry Clin. Neurosci. 14, 377-406. doi: 10.1176/jnp.14.4.377

Rushworth, M. F., Buckley, M. J., Behrens, T. E., Walton, M. E., and Bannerman, D. M. (2007). Functional organization of the medial frontal cortex. Curr. Opin. Neurobiol. 17, 220-227. doi: 10.1016/j.conb.2007.03.001

Schack, B., and Klimesch, W. (2002). Frequency characteristics of evoked and oscillatory electroencephalic activity in a human memory scanning task. Neurosci. Lett. 331, 107-110. doi: 10.1016/S0304-3940(02) 00846-7

Senkowski, D., and Gallinat, J. (2015). Dysfunctional prefrontal gammaband oscillations reflect working memory and other cognitive deficits in schizophrenia. Biol. Psychiatry 77, 1010-1019. doi: 10.1016/j.biopsych.2015.02.034

Senkowski, D., and Herrmann, C. S. (2002). Effects of task difficulty on evoked gamma activity and ERPs in a visual discrimination task. Clin. Neurophysiol. 113, 1742-1753. doi: 10.1016/S1388-2457(02)00266-3

Smith, J. L., Johnstone, S. J., and Barry, R. J. (2004). Inhibitory processing during the Go/NoGo task: an ERP analysis of children with attentiondeficit/hyperactivity disorder. Clin. Neurophysiol. 115, 1320-1331. doi: 10.1016/j.clinph.2003.12.027

Smith, J. L., Johnstone, S. J., and Barry, R. J. (2008). Movement-related potentials in the Go/NoGo task: the P3 reflects both cognitive and motor inhibition. Clin. Neurophysiol. 119, 704-714. doi: 10.1016/j.clinph.2007. 11.042

Sohal, V. S., Zhang, F., Yizhar, O., and Deisseroth, K. (2009). Parvalbumin neurons and gamma rhythms enhance cortical circuit performance. Nature 459, 698-702. doi: 10.1038/nature07991
Stroganova, T. A., Butorina, A. V., Sysoeva, O. V., Prokofyev, A. O., Nikolaeva, A. Y., Tsetlin, M. M., et al. (2015). Altered modulation of gamma oscillation frequency by speed of visual motion in children with autism spectrum disorders. J. Neurodev. Disord. 7:21. doi: 10.1186/s11689-015-9121-x

Tesche, C. D., and Karhu, J. (2000). Theta oscillations index human hippocampal activation during a working memory task. Proc. Natl. Acad. Sci. U.S.A. 97, 919-924. doi: 10.1073/pnas.97.2.919

Tiitinen, H., May, P., and Naatanen, R. (1997). The transient 40-Hz response, mismatch negativity, and attentional processes in humans. Prog. Neuropsychopharmacol. Biol. Psychiatry 21, 751-771. doi: 10.1016/S0278-5846(97)00077-8

Tiitinen, H., Sinkkonen, J., Reinikainen, K., Alho, K., Lavikainen, J., and Naatanen, R. (1993). Selective attention enhances the auditory $40-\mathrm{Hz}$ transient response in humans. Nature 364, 59-60. doi: 10.1038/364059a0

Turken, A. U., and Swick, D. (1999). Response selection in the human anterior cingulate cortex. Nat. Neurosci. 2, 920-924. doi: 10.1038/13224

Van Veen, V., and Carter, C. S. (2002). The timing of action-monitoring processes in the anterior cingulate cortex. J. Cogn. Neurosci. 14, 593-602. doi: $10.1162 / 08989290260045837$

Vinck, M., Womelsdorf, T., Buffalo, E. A., Desimone, R., and Fries, P. (2013). Attentional modulation of cell-class-specific gamma-band synchronization in awake monkey area v4. Neuron 80, 1077-1089. doi: 10.1016/j.neuron.2013.08.019

Walton, M. E., Devlin, J. T., and Rushworth, M. F. (2004). Interactions between decision making and performance monitoring within prefrontal cortex. Nat. Neurosci. 7, 1259-1265. doi: 10.1038/nn1339

Waszak, F., Wascher, E., Keller, P., Koch, I., Aschersleben, G., Rosenbaum, D. A., et al. (2005). Intention-based and stimulus-based mechanisms in action selection. Exp. Brain Res. 162, 346-356. doi: 10.1007/s00221-004-2183-8

Yordanova, J., Banaschewski, T., Kolev, V., Woerner, W., and Rothenberger, A. (2001). Abnormal early stages of task stimulus processing in children with attention-deficit hyperactivity disorder-evidence from event-related gamma oscillations. Clin. Neurophysiol. 112, 1096-1108. doi: 10.1016/S13882457(01)00524-7

Yordanova, J., Kolev, V., and Demiralp, T. (1997). The phase-locking of auditory gamma band responses in humans is sensitive to task processing. Neuroreport 8, 3999-4004. doi: 10.1097/00001756-199712220-00029

Conflict of Interest Statement: The authors declare that the research was conducted in the absence of any commercial or financial relationships that could be construed as a potential conflict of interest.

Copyright (c) 2016 Karch, Loy, Krause, Schwarz, Kiesewetter, Segmiller, Chrobok, Keeser and Pogarell. This is an open-access article distributed under the terms of the Creative Commons Attribution License (CC BY). The use, distribution or reproduction in other forums is permitted, provided the original author(s) or licensor are credited and that the original publication in this journal is cited, in accordance with accepted academic practice. No use, distribution or reproduction is permitted which does not comply with these terms. 